\title{
Manajemen Humas Rebranding Sekolah Tinggi Ilmu Kesehatan (STIKes) 'Aisyiyah Yogyakarta Menjadi Universitas 'Aisyiyah (UNISA) Yogyakarta
}

\author{
Medi Trilaksono Dwi Abadi ${ }^{1}$ \\ ${ }^{1}$ Program Studi Hubungan Masyarakat, Fakultas Ilmu Sosial dan Ilmu Politik, UPN "Veteran" Yogyakarta \\ E-mail: meditrilaksono@upnyk.ac.id
}

\author{
Sinta Maharani ${ }^{2}$ \\ ${ }^{2}$ Biro Hubungan Masyakat dan Protokoler, Universitas 'Aisyiyah \\ E-mail: sinta_maharani@unisayogya.ac.id
}

DOI: https://doi.org/10.21107/ilkom.v15i1.10049

\begin{abstract}
ABSTRAK
Brand atau merek adalah serangkaian entitas yang bisa dilihat dan tidak terlihat yang diatur tata kelolanya untuk membangun identitas dan reputasi terkait produk, jasa, seseorang, serta organisasi yang khas dan mudah dikenali dalam benak pikiran terdalam seseorang. Rebranding adalah proses pengaturan ulang entitas merek yang sudah ada menjadi bertambahdan atau berkurang elemen-elemennya bertujuan untuk meningkatkan daya saing pasar yang ketat. Kajian studi pustaka tentang rebranding organisasi memberikan wawasan bahwa kesuksesan rebranding dipengaruhi oleh perilaku personil internal organisasi terhadap berbagai elemen-elemen yang diatur ulang, dan dipengaruhi juga oleh peran pemangku kepentingan eksternal dalam merespon positif program rebranding organisasi tersebut. Personil internal organisasi menjadi aktor utama yang merepresentasikan nilai-nilai entitas merek termasuk janji utama organisasi yang tersusun dalam visi organisasi. Tujuan penelitian ini adalah untuk memahami tahapan-tahapan yang dilakukan untuk pelaksanaan rebranding dan dampak rebranding terhadap organisasi. Pengumpulan data dilakukan dengan pendekatan studi kasus dan wawancara mendalam terstruktur. Hasil penelitian menunjukkan bahwa keputusan untuk rebranding atau merubah nilai-nilai entitas merek organisasi dipicu oleh perubahan bentuk organisasi yang sekaligus merubah tatanan struktural. Perubahantersebut memiliki pengaruh mendasar pada identitas organisasi dan strategi inti dalam menjalankan tugasnya. Rebranding STIKes 'Aisyiyah Yogyakarta (SAY) menjadi Universitas 'Aisyiyah Yogyakarta (UNISA) berpengaruh pada jumlah mahasiswa baru yang diterima dan nilai-nilai dasar organisasi sehingga terbentuklah penciri baru bagi organisasi. Kesimpulan dari penelitian ini adalah rebranding organisasi bisa sukses terlaksana jika dilakukan dengan hati-hati, terstruktur, dan terukur dengan dukungan penuh dari para aktor penentu kebijakan serta kepedulian personil internal organisasi.
\end{abstract}

Kata Kunci: Corporate rebranding, manajemen humas, peran humas, ekuitas merek, citra merek

\begin{abstract}
A brand is a series of visible and invisible entities whose governance builds an identity and reputation related to a unique and easily recognizable product, service, person, and organization in one's innermost mind. Rebranding is rearranging existing brand entities to increase or decrease the elements to develop a tight market rigid value competitiveness. A literature study on organizational rebranding provides insight that rebranding's success influenced by internal corporate personnel's behaviour towards the various
\end{abstract}

Cite this as :

Abadi, Medi Trilakson Dwi \& Santi Maharani (2021). Manajmen Humas Rebranding Sekolah Tinggi Ilmu Kesehatan (Stikes) 'Aisyiyah Yogyakarta Menjadi Universitas 'Aisyiyah (UNISA) Yogyakarta. Jurnal Komunikasi, 15(1), 83-98. doi: https://doi.org/10.21107/ilkom.v15i1.10049
Article History :

Received February, 24 ${ }^{\text {th }}$ 2021, Acepted March, 15 2021

(c) 2021 Medi Trilaksono Dwi Abadi, Santi Maharani 
elements that rearranged and influenced by external stakeholders' role in responding positively to the organization's rebranding program. The organization's internal personnel become the main actors representing the brand entity's values, including the organization's main promises, which arranged in the organization's vision. This research aims to understand the steps takenfor the implementation of rebranding and the impact of rebranding on the organization. The data was collected using a case study approach and structured in-depth interviews. The results showed that the decision to rebrand or change the values of the organizational brand entity was trigger by changes in the form of the organization, which, at the same time, changed the structural structure. These changes have a fundamental influence on the organization's identity and the core strategy in carrying out its duties. The rebranding of STIKes 'Aisyiyah Yogyakarta (SAY) into' Aisyiyah Yogyakarta University (UNISA) affects thenumber of new students accepted and the fundamental values of the organization to form a new character for the organization. This study concludes that organizational rebranding can be successful if carried out carefully, structured and measuredly with the full support of policy-making actors and internal corporate personnel's care.

Keywords: corporate rebranding, public relations role, public relations management, brand equity, brand image

\section{PENDAHULUAN}

Persaingan bidang pendidikan memasuki era borderless world yaitu dimana batas kedaulatan bangsa/negaraseolah tak lagi ada, kecuali hanya infrastruktur fisik dan kebijakan-kebijakan formal lintas teritori. Borderless world ini sebagai akibat dari arus globalisasi di hampir segala sektor kehidupan (Paasi, 2018). Globalisasi juga dipengaruhi oleh perkembangan teknologi informasi dan komunikasi yang begitu cepat, sehingga segala aktifitas harian kehidupan pribadi maupun perkantoran pun harus beradaptasi dengan pendekatan teknologi pula. Persaingan bisnis global juga menyasar di lingkungan pendidikan, khususnya perguruan tinggi. Berbagai jenis kampus dari akademi hingga universitas saling bersaing, berkompetisi membangun keunggulan masing-masing (Sharma et al.,2017).

Persaingan bisnis antar kampus ini juga dipengaruhi oleh peran divisi humas kampus dalam mengolah pesan-pesan atau nilai-nilai organisasi secara strategis hasil diskusi dengan jajaran pimpinan kampus, sehingga dampak terhadap kampus juga positif. Setiap perguruan tinggi memiliki tantangan yang mirip yaitu diharuskan membuat unsur pembeda antar kampus. Hal ini bertujuan agar masing-masing kampus mendapatkan target pasar yaitu mahasiswa sesuai dengan nilai-nilai unggulan kampusnya (Flecknoe et al.,2017)
Brand merupakan salah satu nilai aset tidak kasat mata bagian dari identitas yang dimiliki oleh sebuah organisasi, dimana organisasi harus mengelola dan mengatur nilai-nilai yang terkandung didalamnya. Brand atau merek dapat menggambarkan perilaku bisnis organisasi tersebut. Brand merupakan sebuah nama, istilah, tanda, simbol, atau desain, atau kombinasi dari unsur-unsur tersebut, yang dimaksudkan untuk mengidentifikasi barang dan jasa dari seorang penjual atau beberapa penjual serta untuk membedakan penjual tersebut dari para pesaingnya.(Keller, 2007)

Perkembangan teknologi informasi dan komunikasi memudahkan masyarakat mengakses informasi tentang keunggulan berbagai kampus. Peningkatan aktifitas pencarian informasi seputar kampus biasanya terjadi pada masa pendaftaran mahasiswa baru kurun waktu 10 bulan dari bulan Desember hingga September diselasela masa ujian akhir sekolah menengah atas. Pihak kampus yang proaktif menyiapkan segala informasi yang dibutuhkan masyarakat terkait nilai-nilai dasar hingga unggulan kampus akan mendapat dampak yang positif dalam mempengaruhi benak pikiran calon mahasiswa baru. Masyarakat yang aktif mencari informasi kampus biasanya akan berkunjung ke portal resmi kampus dan media-media informasi pendukung lainnya 
seperti media sosial dan media tools konvensional seperti: brosur, iklan radio, dan iklan televisi.

Branding atau internalisasi nilainilai khusus pada organisasi merupakan hal yang sangat penting. Hal ini dikarenakan sebuah brand dapat memberikan kesan yang baik maupun buruk tentang sebuah organisasi, baik itu organisasi yang baru memulai bisnisnya maupun organisasi yang sudah berjalan lama. Jika sebuah organisasi sudah ada danbrand yang dimilikinya sudah dikenal, namun ingin memberikan kesan yang berbeda dari sebelumnya, maka perlu dilakukan inovasi. Rebranding adalah proses memperbaharui dan memodifikasi sebagian maupun total dari identitas suatu organisasi yang bertujuan menjadikan organisasi tersebut lebih baik dan tetap sesuai visi awal organisasi, yaitu berorientasi pada profit atau keuntungan. Perubahan nama dilakukan agar organisasi dapat mengenalkan dirinya dalam cakupan skala yang lebih luas pada berbagai lapisan masyarakat.
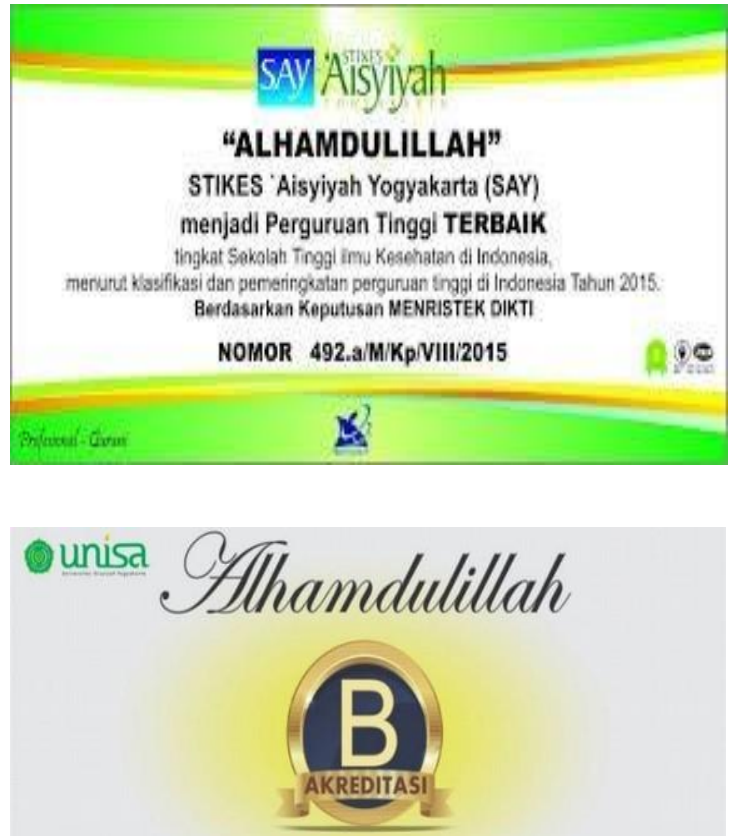

Universitas 'Aisyiyah Yogyakarta Mendapatkan Nilai Akreditasi B Berdasarkan SK BAN PT No. 3566/SK/BAN-PT/Akred/PT/X/2017 Terimakasih Atas Do'a dan Dukungan Seluruh Civitas Akademika Universitas 'Aisyiyah Yogyakarta

Gambar 1. Masa akhir STIKes meraih prestasi sebagai STIKes terbaik dan EraUNISA meraih akreditasi B.
Perkembangan industri pendidikan tinggi menuntut kampus beradaptasi pada situasi pasar (kebutuhan bidang ilmu) dengan menyediakan berbagai pilihan jurusan bagi para calon mahasiswa. Salah satu unsur motivasi calon mahasiswa memilih tempat kuliah adalah kepercayaancalon mahasiswa melalui reputasi kampus dan jenis organisasinya baik yang swasta maupun milik pemerintah (kampus negeri).

Persaingan dalam mencari mahasiswa ini dipengaruhi oleh berbagai media komunikasi yang digunakan masing-masing kampus dan tentu saja juga pengaruh utamanya berasal dari pemahaman para pimpinan kampus akan pentingnya branding kampus. Branding kampus yang tepat bertujuan agar kampus memiliki penciri yang khas sehingga bisa memunculkan perbedaan dari para kampus pesaingnya. Implikasi dari munculnya pembeda yang khas ini yaitu pada pertambahan jumlah mahasiswa pada kampus yang melakukan branding dengan tepat.(Edhy, 2015).

Tujuan lain dari rebranding kampus yaitu untuk membangun kemudahan dan meningkatkan kualitas pendidikan para mahasiswa dan calon mahasiswa pada kampus yang bersangkutan. (Tribunnews, 2019). Rebranding perlu dilakukan manakala organisasi melalukan perubahan total atau memperbaharui brand yang sudah dikenal agar menjadi lebih baik menyesuaikan situasi perkembangan zaman. Rebranding tidak lepas dari tujuan dasar organisasi perguruan tinggi yaitu profit. Peningkatan profit yang diperoleh hasil dari penambahan jumlah pendaftar dan jumlah mahasiswa pada perguruan tinggi yang melakukan rebranding. (Kusumawati, 2017).

Rebranding memberikan dampak positif sebesar 52,3\% terhadap brand image perguruan tinggi yang mencakup aspek repositioning, redesign, renaming, dan relaunch. Hal ini juga membuat mahasiswa memberikan respon yang baik atas tindakan kapusnya melakukan rebranding. Citra kampus menjadi lebih baik. (Suryawardani \& Mariastuti, 2015) 
'Aisyiyah sebagai yayasan pemilik STIKes 'Aisyiyah melihat peluang besarbagi organisasi mampu bersaing pada pasar persaingan pendidikan tinggi dengan bentuk universitas. Berdasarkan hal tersebut, 'Aisyiyah memutuskan pentingnya rebranding sebagai strategi penunjang pengembangan kampus daribentuk sekolah tinggi menjadi universitas.

STIKes 'Aisyiyah Yogyakarta terbukti berhasil membangun persepsi yang positif di benak calon mahasiswa, khususnya yang minat pada bidang ilmu kesehatan. Pembuktian 'Aisyiyah ditandai dengan capaian STIKes 'Aisyiyah Yogyakarta yang dinobatkan sebagai Sekolah Tinggi Ilmu Kesehatan terbaik oleh Kemenristek Dikti pada akhir tahun 2015. Disamping sebagai STIKes terbaik juga mendapat penilaian Akreditasi B, sehingga calon mahasiswa dan seluruh civitasnya pun memiliki kebanggan tersendiri. Hal ini menjadi bukti nyata STIKes 'Aisyiyah sebagai kampus kesehatan yang mempunyai kehandalan dan keunggulan pada setiap aspek organisasinya.

Iklim kompetisi yang ketat akan menyulitkan perkembangan kampus jika tidak memiliki kemampuan adaptasi diri dengan cepat dan mampu berkembang seiring dengan berbagai tuntutan pemangku kepentingan. Situasi ini berlaku hampir di seluruh kampus dengan berbagai jenis bentuk organisasinya. Saat ini paradigma dalam memandang pendidikan mulai bergeser, yang awalnya pendidikan dilihat dan dikaji dari aspek sosial, sekarang orang melihat pendidikan lebih pada sebuah korporasi. Artinya, lembaga pendidikan dalam hal ini perguruan tinggi dipahami sebagai suatu organisasi produksi yang menghasilkan jasa pendidikan yang dibeli oleh parakonsumen yaitu mahasiswa melalui orang tua. Perguruan tinggi harus berusaha mencapai keunggulan memberikan layanan prima dan menghasilkan lulusan yang berkualitas. Karena kualitas layanan perguruan tinggi berbanding lurus dengan kepercayaan peminat layanan jasa pendidikan (mahasiswa dan orang tua). Pelayanan pendidikan/kemahasiswaan yang berkualitas meningkatkan jumlah animo pendaftar pada calon mahasiswa dan orang tua.

Pertumbuhan perguruan tinggidengan situasi persaingan yang ketat mendorong sebuah brand/merek dalam hal ini yaitu reputasi perguruan tinggi pendidikan harus dikemas strategis dan taktis agar menarik serta memenangkan hati pelanggan atau calon mahasiswa dan orang tua. Kekuatan emosional menjadi aspek yang penting saat merek-merek atau reputasi nama kampus lain lebih sering fokus pada hal-hal seperti kualitas dan biaya. Memanfaatkan pola pikir terkait adanya karakteristik dan perilaku audiens adalah contoh dari pendekatan emosional. Strategi branding sebenarnya berkaitandengan pikiran dan emosi dari para konsumen sehingga menciptakanketerikatan antara konsumen dengan merek.

Persaingan ketat kampus dengan bentuk organisasi berupa universitas menuntut 'Aisyiyah bertindak dengan cermat membangun unsur pembedasebagai strategi diferensiasi produk. Diferensiasi yang disepakati jajaran pimpinan universitas dan pimpinanyayasan adalah menjadikan UNISA sebagai satu-satunya kampus kesehatan yang dikelola oleh organisasi perempuan Islam terbesar di Indonesia. Perubahan bentuk dari sekolah tinggi menjadi universitas membuat unit kerja Hubungan Masyarakat (Humas) harus jeli melihat situasi pasar dan organisasi UNISA itu sendiri. Penyusunan program kerja yangstrategis dari unit humas menjadi penunjang jajaran pimpinan dalam menentukan kebijakan yang tepat agar rebranding STIKes 'Aisyiyah menjadi UNISA memiliki dampak positif yang lebih besar bagi organisasi dan para pemangku kepentingan

\section{METODE PENELITIAN}

Penelitian ini menggunakan metode penelitian deskriptif kualitatif dan proses analisis data hasil wawancara dengan cara membandingkan simpulan dari masing- 
masing informan serta menggunakan logika ilmiah dalam memahami dinamika hubungan fenomena yang muncul (Rakhmat, 2004). Penelitian ini tidak menguji hipotesis atau membuat prediksi hanya pemaparan fenomena hubungan antar manusia dalam lingkup pekerjaannya dalam mengelola sebuah organisasi/instansi. (Abrudan, 2009)

Peneliti menggunakan teknikobservasi terbuka dengan menyatakan secara terbuka kepada informan/narasumber bahwa peneliti sedang melakukan penelitian. Peneliyi juga melengkapi data dengan studi pustaka. Studi pustaka yang dilakukan adalah dengan mempelajari dan memahami data yang diperoleh dari Unisa (Universitas 'Aisyiyah) Yogyakarta, mempelajari buku referensi, karya tulis ilmiah, dan karya tulis popular yang relevan dengan kegiatan rebranding/brandrevitalization.

Teknik analisis data dalam penelitian ini melalui triangulasi yaitu mengolah dan sinkronisasi semua data yang diperoleh, baik primer maupun sekunder guna menarik kesimpulan hasildari penelitian.

Penentuan subjek penelitian dalam pengumpulan data di lapangan dilakukan dengan cara memilih informan yang representatif dari organisasi Unisa. Dalam penelitian ini yang menjadi subyek penelitian dari Unisa adalah:

1. Ketua yayasan 'Aisyiyah selaku perwakilan organisasi yang memiliki kampus,

2. Pimpinan tinggi universitas meliputi: Rektor dan Wakil Rektor 2 Bidang Keuangan,

3. Kepala Badan Perencanaan dan Pengembangan, dan

4. Kepala unit kerja Biro Humas dan Protokoler.

Objek penelitian dalam penelitianini adalah tentang proses rebranding yaitu penggantian identitas organisasi dari Sekolah Tinggi Ilmu Kesehatan (STIKes) 'Aisyiyah
Yogyakarta menjadiUniversitas 'Aisyiyah (Unisa) Yogyakarta yang difokuskan pada manajemen humas dalam program rebranding kampus

\section{HASIL DAN PEMBAHASAN}

Hubungan masyarakat adalah fungsi manajemen yang membangun dan memelihara hubungan yang saling menguntungkan antara organisasi dan publik yang menjadi sandaran keberhasilan atau kegagalannya (Broom \&Sha, 2013). Program pengembangan organisasi yang didukung oleh pemilik, yakni yayasan akan lebih optimal jika bisa tersampaikan secara menyeluruh kepada semua pemangku kepentingan internal daneksternal.

Unit kerja hubungan masyarakat (divisi humas), dalam hal ini Biro Humas dan Protokoler Unisa berperan sebagai agen yang bertugas menjembatani informasi/program kerja dari jajaran pimpinan yayasan, pimpinan tinggi universitas, pemangku kepentingan internal, dan pemangku kepentingan eksternal. Secara umum, tugas dan fungsi divisi humas adalah sebagai teknisi komunikasi dan pengelola informasi (Beresford \& Schwarz, 2014)

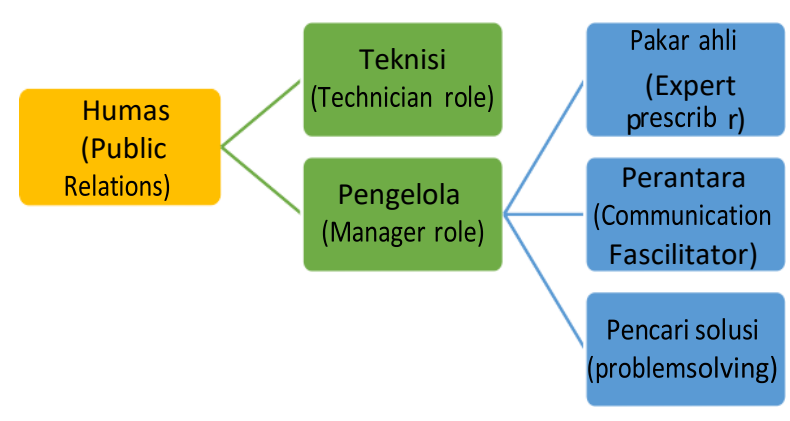

Gambar 2. Model Peran Humas

Berikut ini adalah informan representatifdari Unisa:

- Informan 1

$\begin{array}{ll}\text { Nama } & \text { : Dra. Siti Noordjannah } \\ & \text { Djohantini, M.M., M.Si. } \\ \text { Jabatan } & \text { : Ketua Umum Pimpinan } \\ & \text { Pusat 'Aisyiyah }\end{array}$


- Informan 2

Nama : Warsiti, M.Kep, Sp.Mat

Jabatan : Rektor

- Informan 3

Nama : Yuli Isnaeni, M.Kep, Sp.Kom

Jabatan : Wakil Rektor 2 Bidang Keuangan

- Informan 4

Nama : Sulistyaningsih, M.H.Kes

Jabatan : Kepala Badan Perencanaan dan Pengembangan

- Informan 5

Nama : Sinta Maharani, S.Sos

Jabatan : Kepala Biro Hubungan Masyarakat dan Protokoler

Praktisi humas yang bekerja pada unit humas sebuah organisasi peran utamanya adalah menyediakan informasi- informasi hasil dari pengumpulan dananalisis data di lapangan terkait kondisi komunikasi internal dan eksternal organsisasi. Informasi tersebut menjadi alat untuk bahan pertimbangan jajaran pimpinan dalam membangun kebijakan, menyediakan pelayanan, dan membentuk perilaku organisasi yang sesuai dengan visiorganisasi.

Tujuan utamanya adalah mengoptimalkan potensi yang dimiliki organisasi sehingga kinerjanya bisa berjalan efektif, efisien, dan mencapaitarget yang telah ditentutkan. Sinta menyatakan, Humas adalah supporting system pimpinan. Karena humas bisa menjadi jalan tengah untuk menyampaikan kebijakan pimpinan kepada civitas Unisa

Biro Humas Unisa beperan sebagai penyalur informasi dari 2 sisi yaitu AtasanBawahan dan Internal-Eksternal. Program kerja yayasan dengan jajaran pimpinan Universitas adalah mengembangkan STIKes berubah menjadi universitas dengan berbagai tuntutan kebutuhan pasar dan peraturan pemerintah yang berlaku. Menurut Siti, STIKes punya potensi besar untuk dikembangkan menjadi universitas, karena perguruan tinggi yang dikelola organisasi perempuankhususnya yang bernuansa Islami hanya sedikit. 'Aisyiyah memiliki 7 cabang kampus dengan jenjang sekolah tinggi atau akademi. Sehingga berkembang menjadi universitas adalah keniscayaan, terlebih lagi STIKes 'Aisyiyah Yogyakarta sudah memiliki kekhasan tersendiri yaitu kampus dengan wawasan kesehatan. Perubahan menjadi universitas yang fokus pada bidang kesehatan menjadi keunikan.

TIKes 'Aisyiyah resmi berubah menjadi Universitas 'Aisyiyah (Unisa) pada bulan Maret 2016 berdasarkan surat keputusan Menteri Riset, Teknologi, dan Pendidikan Tinggi waktu itu. Perubahan menjadi Unisa ini hanya kurun waktu 3 bulan sejak STIKes 'Aisyiyah meraih prestasi sebagai STIKes terbaik di Indonesia berdasarkan pada hasil pemeringkatan perguruan tinggi swasta oleh Kementerian Riset, Teknologi, dan Pendidikan Tinggi.

Polemik terjadi ketika satu sisi keinginan mempertahankan prestasi atau berkembang menjadi universitas dengan beroperasi membawa nama baru yaituUnisa. Warsiti menyampaikan, muncul dilematis ketika STIKes meraih prestasi sebagai STIKes terbaik di akhir tahun 2015, namun di kemudian hari pada Maret 2016 surat ijin operasional bentuk universitas juga sudah terbit dengan nama Universitas 'Aisyiyah yang kemudian disingkat dengan nama Unisa. Dilematis tersebut menjadi tantangan yang menjadi peluang untuk Unisa memasuki persaingan baru perguruan tinggi tingkat universitas. Persoalan promosi pergantian identitas menjadi tugas utama divisi humas, karena hal itu juga sekaligus berkaitan dengan kegiatan promosi dalam rangkapenerimaan mahasiswa baru.

Nuansa kehidupan berorganisasi jauh berbeda, ketika era STIKes semua mahasiswa ketika kuliah berseragam dan kehidupan interaksi antar civitas didominasi oleh 
personil berlatarbelakang ilmu kesehatan. Ketika menjadi Unisa, keberadaan personil dari bidang ilmu saintek dan sosial humaniora mewarnai situasi interaksi antar civitas, dan suasana pergaulan antar mahasiswa pun juga diwarnai dengan visual mahasiswa berpakaian bebas tidak berseragam. Perubahan menjadi Unisa kala itu memasuki masa Penerimaan Mahasiswa.

Baru (PMB) gelombang kedua, sehingga perubahan struktur organisasi pun berdampak pada unit kerja humas yang kala itu PMB dikelola kepanitiaan adhoc, di masa baru menjadi Unisa pengelolaan PMB ada pada unit kerja humas dengan nama Biro Admisi dan Humas.

\section{Rebranding}

Rebranding juga disebut dengan istilah brand revitalization (Miller et al., 2014b). Revitalisasi brand/merek dilakukan sebagai bentuk respon organisasi/instansi pemilik brand/merek atas tuntutan perubahan zaman dan situasi sosial kemasyarakatan. Tujuan rebranding/brand revitalization adalah untuk menghidupkan kembali atau memperbaiki penurunan kualitas pada suatu brand/merek agar kembali dikenal dan merasuki pikiran lagi para pemangku kepentingan internal dan eksternal pada organisasi/instansi pemilik brand/merek tersebut.

Rebranding merupakan proses perubahan identitas baru termasuk namabaru organisasi sebagai cerminan atas nilai keunikan sekaligus pembeda dari para pesaingnya. Rebranding dibagi menjadi 4 tahapan yaitu (Muzellec \& Lambkin, 2008)

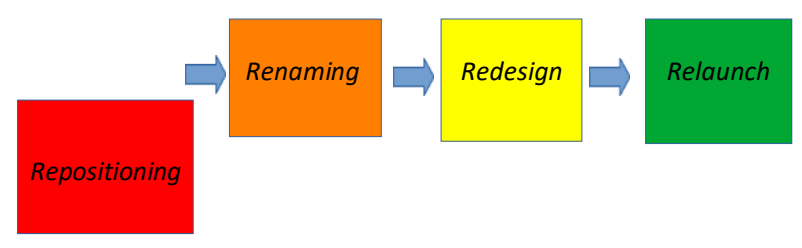

Gambar 3. Tahapan Rebranding
'Aisyiyah adalah organisasi perempuan yang memfokuskan kegiatannya pada kegiatan sosial dan religi terkait kesetaraan gender yang berkembang di kalangan masyarakat khususnya di kota Yogyakarta. 'Aisyiyah merupakan anak organisasi dari organisasi Islam yaitu Muhammadiyah. 'Aisyiyahmemiliki cita-cita ikut andil dalam proses mencerdaskan bangsa, hal ini terbukti dari kiprahnya dalam membangun sektor pendidikan yang diawali dari pendidikan anak usia dini yang diberi nama TK ABA (Taman Kanak-kanak 'Aisyiyah Busthtanul Athfal).

Cita-cita tersebut dilandasi niat luhur dan atas dorongan serta motivasi Allah yang termuat dalam Al-quran surat Al-Mujadalah ayat 11, yang artinya "Allah akan meninggikan derajat orang- orang mukmin dan orang-orang yang diberi ilmu pengetahuan beberapa derajat (Depag, 2007).

Bertolak dari dorongan dan motivasi tersebut, 'Aisyiyah dalam menyelenggarakan pendidikan dimulai dari taman kanak-kanak sampai tingkat pendidikan tinggi, dilaksanakan dengan tekun dan penuh tanggungjawab. tak ada rentang waktu tanpa pendidikan. Bukti nyata jam terbang 'Aisyiyah mumpuni dalam bidang pendidikan selain pendidikan anak usia dini yaitu kiprahnya dalam mengembangkan institusi pendidikan tinggi yang berkembang dengan nama Sekolah Tinggi Ilmu Kesehatan (STIKes) 'Aisyiyah Yogyakarta yang berlokasi di kawasan kecamatanNgampilan, kota Yogyakarta.

Perkembangan institusi pendidikan tinggi 'Aisyiyah berawal dari terbentuknya Sekolah Bidan 'Aisyiyah Rumah Sakit Muhammadiyah pada tahun 1963. Tahun 1998 Akper 'Aisyiyah dikonversi menjadi Akademi Kebidanan (Akbid) 'Aisyiyah Yogyakarta sesuai dengan SK Menkes RI No. HK 00.06.1.3.02187. Tahun 2003 Akbid 'Aisyiyah Yogyakartadikembangkan menjadi Sekolah Tinggi Ilmu Kesehatan 'Aisyiyah Yogyakarta sesuai dengan SK mendiknas RI No 181/D/O/2003 tanggal 14 Oktober 2003. 
Memasuki tahun 2016 adalah momentum utama pihak yayasan dan pengurus pendidikan tinggi 'Aisyiyah memproses tahapan-tahapan rebranding secara lebih mendalam. Tahun 2016, tepatnya pada tanggal 10 Maret 2016, STIKES 'Aisyiyah Yogyakarta berubah bentuk menjadi Universitas 'Aisyiyah (UNISA) Yogyakarta melalui Surat Keputusan (SK) Kemenristek Dikti nomor 109/KPT/I/2016.

Berdasarkan pemaparan diatas, maka secara umum rebranding yang diteliti dapat disebut sebagai corporate rebranding. Corporate rebranding dapatdilihat dari dua sisi, yaitu: Pertama, berkaitan dengan perubahan corporate visual identity, termasuk nama organisasi dan perubahan logo (Miller et al., 2014a). Kedua, berkaitan dengan proses internal organisasi/instansi pemilik brand/merek,mencakup perubahan nilai-nilai mutu atau budaya organisasi, partisipasi pemangku kepentingan internal dan juga sistem komunikasi internal organisasi/instansi (Goi \& Goi, 2011).

Corporate rebranding yangdilakukan oleh Sekolah Tinggi Ilmu Kesehatan 'Aisyiyah Yogyakarta (STIKes 'Aisyiyah Yogyakarta) menjadi Unisa (Universitas'Aisyiyah) mencakup kedua sisi tersebut diatas, yang dibahas dengan perspektif tahapan-tahapan rebranding,yaitu:

\section{Brand Repositioning}

Brand Repositioning proses ini merupakan proses mendasar yang dilakukan pertama kali oleh organisasi/instansi pada saat memutuskan rebranding/revitalisasi merek. Pada tahapan reposisi, pemilik brand/merek mengatur ulang kebutuhan krusial yang mampu menstimulus memori ingatan para pemangku kepentingan internal dan eksternalterkait nilai-nilai positif brand/merek yang dimiliki.

\footnotetext{
Sekolah Tinggi Ilmu Kesehatan 'Aisyiyah Yogyakarta (STIKes
}

'Aisyiyah Yogyakarta) adalahperubahan konsep dasar organisasi dan jenis bidang ilmu yang disajikan tidak hanya ilmu kesehatan tetapi jugasaintek dan sosial humaniora, serta perluasan target pemasaran.

Hal tersebut berdampak pada penambahan jumlah mahasiswa yang menempuh studi di Sekolah Tinggillmu Kesehatan 'Aisyiyah Yogyakarta (STIKes 'Aisyiyah Yogyakarta). Berbagai dukungan kebijakan termasuk pendanaan dan infrastruktur juga disiapkan misalnya: pembangunan gedung baru 6 lantai sebagai penunjang kegiatan akademik dari semua bidang ilmu yang bertambah.

Proses rebranding tidak bisa lepas dari strategi komunikasi yang tepat agarpelaksanaannya bisa berjalan dengan baik dan lancar dengan pemenuhantarget sesuai yang direncanakan. Strategi komunikasi memiliki aspek- aspek yang relevan dengan segala upaya guna mencapai dan mendukung suatu tujuan dengan membutuhkan koordinasi tindakan, pesan, citra, danbentuk-bentuk lain yang membangun keterpautan untuk menginformasikan, mempengaruhi, dan mengajak khalayak tertentu agar mendukung tujuan organisasi.

Perubahan yang dilakukan tersebut tidak mengubah visi dan arah tujuan organisasi secara revolusioner, namun perubahan yang dilakukan lebih bersifat pada pengembangan dengan penajaman pada aspek khusus bidang kesehatan yang didukung bidang ilmu saintek dan sosial humaniora. Atas dasar pemikiran tersebut, maka visi organisasi tetap mencaup tema "universitas berwawasankesehatan dan berlandaskan pada nilai- nilai Islam Berkemajuan". Jika pada masa STIKes 'Aisyiyah Yogyakarta, tema visi tersebut menjadi normative/umum, pada masa identitas yang baru yaitu UNISA (Universitas 'Aisyiyah), tema visi tersebut menjadi 
penciri kekhususan pembeda dengan organisasi pendidikan tinggi lain yang juga mengusung tema kampus kesehatan.

Penciri kekhususan yang dimaksudyaitu, keberadaan bidang ilmu saintek dan ekonomi sosial humaniora yang dibagi menjadi 2 kelompok yaitu: Fakultas Sains dan Teknologi (FST) meliputi program studi: Arsitek dan Bioteknologi. Fakultas Ekonomi, Ilmu Sosial, dan Humaniora (FEISHum) meliputi program studi: Akuntansi, Manajemen, Administrasi Publik, Komunikasi, dan Psikologi. Seluruh program studi (prodi) baru tersebutadalah program sarjana, dan seluruhnya juga mengusung kekhususan visi keilmuan yang sama yaitu berwawasan kesehatan dan berdasarkan pada nilai- nilai Islam Berkemajuan. Sebagai contoh: Prodi Komunikasi diarahkan memfokuskan visi keilmuannya pada kajian-kajian komunikasi kesehatan/komunikasi terapeutik dengan baluran nilai-nilai Islam sesuai Al-quran dan hadits-hadits yang shahih.

STIKes Repositioning yang dilakukan menitikberatkan pada perubahan bentuk organisasi dari sekolah tinggi menjadi Uuniversitas yang ditandai dengan penambahan dua bidang ilmu yang dibentuk dalam 2 fakultas yaitu Sains dan Teknologi (FST) dan Ekonomi, Ilmu Sosial, dan Humaniora(FEISHum). Perubahan bentuk organisasi menjadi universitas, secara otomatis berdampak pada perluasantarget market dari yang awalnya hanyapeminatan ilmu kesehatan saja, setelah repositioning bertambah pada bidang saintek dan ekonomi, sosial, dan humaniora.

Warsiti menyampaikan, Unisa memiliki modal dasar yang kuat yaitu meraih prestasi sebagai STIKes terbaik akhir tahun 2015 yang kemudian tahun 2016 menjadi universitas, pimpinan yayasan dan pimpinan universitas bersepakat menjaga amanah prestasi tersebut dengan cara membangun ciri khas Unisa tetap sebagai kampus yang berwawasan kesehatan. Hal ini juga diterapkan pada dua fakultas baru yaitu saintek dan ekonomi sosial humaniora yang bernuasa kesehatan. Misalnya: di saintek kajian yang dibahas adalah seputar teknologi bidang kesehatan. Sedangkan di ekonomi sosial humaniora kajian yang dibahas juga berwawasan kesehatan seperti komunikasi kesehatan, keuangan rumah sakit, dan kebijakan bidang kesehatan.

Proses repositioning juga mencakup pada perubahan skema struktur organisasi kampus menjadi lebih besar (kompleks), hal ini dikarenakan adanya pemisahan unit kerja lama yang dinilai akan lebihoptimal kinerjanya jika dilakukan pemisahan struktur organisasi, sebagai contoh yaitu pada unit kerja Kantor Kerjasama Internasional dan Humas (KKIH) ini berlaku pada masa STIKes 'Aisyiyah Yogyakarta.

Pada masa UNISA Yogyakarta, unit kerja KKIH dipisah menjadi dua unit kerja menjadi Biro Kerjasama dan Urusan Internasional (BKUI) dan Biro Admisi dan Hubungan Masyarakat (BAH). Memasuki usia empat tahun perubahan, UNISA kembali membuat terobosan dalam hal repositioning. Adanya perubahan nama dan tugasfungsi unit kerja humas dari Biro. Admisi Humas (BAH) berubah menjadi Biro Humas dan Protokoler (BHP).

Tugas pokok dan fungsi BHP pada kegiatan komunikasi internal dan eksternal para pemangku kepentingan yang tidak lagi mengelola Penerimaan Mahasiswa Baru (PMB), dimana PMB berubah menjadi dikelola oleh Biro Admisi tersendiri. Perubahan struktur organisasi secara umum dilakukan agar tujuan utama organisasi/instansi yaitu mewujudkan visi sebagai kampus berwawasan kesehatan dengan baluran 
nilai-nilai Islam Berkemajuan lebih mudah dicapai.

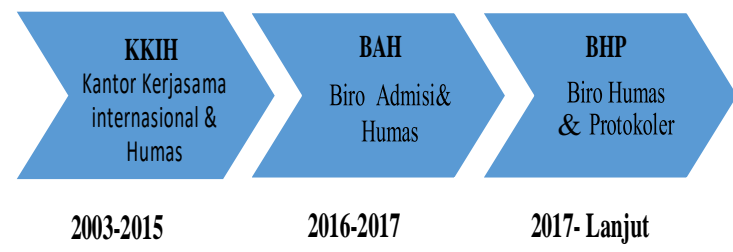

Gambar 4. Transformasi unit kerja humas

Sulis menyampaikan, reposisi STIKes berubah seiring perubahannya menjadi Unisa. Zona persainganmenjadi lebih luas karena adanya penambahan 10 program studi baru yang terbagi dalam 2 fakultas baru yaitusaintek dan ekonomi sosial humaniora. Menjadi tugas humas dalam mengelola kegiatan promosi dan admisi, karena penambahan 2 fakultas juga otomatis menambah porsi mahasiswa dalam penerimaan mahasiswa baru (PMB).

Perubahan menjadi Unisa diuntungkan dengan masih berlakunya masa pendaftaran mahasiswa, sehingga tahun pertama beroperasi dengan identitas baru pun Unisa tetap bisa memperoleh tambahan mahasiswa baru pada 10progam studi yang baru.

\section{Brand Renaming}

Brand Renaming merupakan yang paling komprehensif dan paling beresiko dalam proses rebranding. Renaming menjadi tahapan dimana keputusan membuat nama baru adalah solusi terbaik untuk menghidupkan identitas baru di benak pikiran para pemangku kepentingan. Penggantian nama organisasi/instansi pemilik merek sekaligus menjadi tanda pemberlakuan arah dan tujuan organisasi yang barudemi penambahan aspek capaian- capaian yang tidak bisa disasar dengan nama organisasi yang lama.

Tindakan yang dilakukan adalah mengganti nama Sekol ah Tinggi Ilmu $\begin{array}{lrr}\text { Kese hatan } & \text { (STIKes } & \text { 'Aisyiyah } \\ \text { Yogyakarta) } & \text { berubah } & \text { menjadi } \\ \text { Universitas } & \text { 'Aisyiyah } & \text { (UNISA) }\end{array}$

Yogyakarta. Proses penggantian nama baru organisasi/ instansi, khususnya pembuatan nama terkait pema saran yang biasa nya berup a akron im, tidak serta merta langsung jadi, namun melalui proses bertahap dengan ujicoba penamaan yang berganti beberapa kali. Ujicoba penggantian nama meliputi: UAY (Universitas 'Aisyiyah Yogyakarta), UNISAY (gabungan dari UNISA dan SAY (STIKes 'Asyiyah Yogyakarta)), dan UNISA (Universitas 'Aisyiyah)

Keputusan menghilangkan kata Sekolah Tinggi Ilmu Kesehatan menjadi tanda utama bahwa UNISA Yogyakarta menjadi kampuspendidikan tinggi yang normatif seperti kampus pada umumnya, karena bidang ilmu yang ditawarkan pada program Penerimaan Mahasiswa Baru (PMB) menjadi lebih beragam yang terkategorimenjadi 3 fakultas.

Seluruh program studi (prodi) yang sebelumnya ditawarkan pada masa STIKes melebur menjadi satu fakultas yaitu Fakultas Ilmu Kesehatan (FIKes) meliputi: Kebidanan, Ilmu Keperawatan, Fisioterapi, Radioterapi \& Radiodiagnostik, dan Analis Kesehatan. Fakultas Sains dan Teknologi (FST) meliputi program studi: Arsitek dan Bioteknologi. Fakultas Ekonomi, Ilmu Sosial, dan Humaniora (FEISHum) meliputi program studi: Akuntansi, Manajemen, Administrasi Publik, Komunikasi, danPsikologi.

Pada tahap renaming ini, pihak yayasan dan jajaran pimpinan universitas bersepakat memilih akronim UNISA sebagai nama/ikon pemasaran berdasarkan pada penamaan UNISA sebagai bentuk turunan dari surat dalam Al-quran yaitu An-Nisa yang berarti Wanita. Hal ini berkenaan dengan, STIKes 'Aisyiyah Yogyakarta yang 
berubah menjadi UNISA Yogyakarta adalah satu-satunya perguruan tinggi jenis universitas yang dikelola oleh organisasi perempuan yang bercorak Islam di Indonesia. UNISA Yogyakarta selain mencirikan organisasi sebagai kampus berwawasan kesehatan, juga sekaligus menerapkan nilai-nilai Islam Berkemajuan yang menjadi bagian dari visi organisasi.

Renaming yang dilakukan STIKes 'Aisyiyah Yogyakarta juga menyasar pada nilai-nilai budaya organisasi yang sebelumnya di masa STIKes 'Aisyiyah Yogyakarta disebut dengan TPIMEC (Trust; Profesional; Iman-Ilmu-Amal; Morality; Excellent; dan Customer Focus) diganti menjadi @ Prime (Amanah; Profesional; ImanIlmiah- Amaliah; Moralitas; dan Excellent). Siti menyampaikan, penggantiannama STIKes menjadi Unisa ini berdasarkan hasil diskusi pimpinan yayasan bersama dengan pimpinan universitas yang sebelumnya muncul beberapa alternatif nama yaitu: UAY (Universitas 'Aisyiyah Yogyakarta), Unisay (Unisa Yogyakarta), dan Unisa. Disepakati menggunakan nama Unisa karena ini yang paling sesuai denganciri khas 'Aisyiyah yaitu perempuan Islam yang merujuk pada surat An-Nisayang berarti perempuan-perempuan.

Sulis menyampaikan, nilai budaya mutu STIKes berubah menyesuaikan kebutuhan dan identitas Unisa.Perubahan nilai budaya mutu dari TPIMEC (Trust; Profesional; Iman- ilmuamaliah; Moralitas; Excellence; dan Customer Focus) menjadi @Prime (Amanah; Profesional; Iman-ilmiahamaliah; Moralitas; dan Excellence).

Sinta menyampaikan, perubahan nilai budaya mutu menjadi @Prime juga menjadi bagian dari instrumen promosi identitas baru Unisa. Hal ini dilakukan melalui menyempatkan tulisan @Prime (Amanah; Profesional; Iman-ilmiah- amaliah; Moralitas; dan Excellence) pada media promosi yang memiliki area desain relatif luas seperti: tas promosi/goodie bag, kalender, payung, bloknote, dan mug/tumbler.

Sinta menyampaikan, Unisa membutuhkan seperangkat media promosi baru dengan tema Unisa untuk pengenalan identitas baru. Unit kerja humas mengakomodir kepentingan tersebut melalui pembuatan berbagai jenis media promosi, diantaranya: booklet/brosur promosi penerimaan mahasiswa baru (PMB), video profil universitas, dan video profil program studi.

\section{Brand Redesign}

Brand Redesign adalah mendesainulang logo, gaya dan pesan seiring dengan menciptakan citra merek baru. Nama, slogan, dan logo merupakan elemen penting dalam merancang sebuah merek, karena merupakan kebutuhan organisasi/ instansi untuk membangun visi, misi, dan nilai-nilaidalam proses rebranding.

Tindakan yang dilakukan STIKes 'Aisyiyah Yogyakarta adalah mendesain ulang logo dan media informasi multi platform, seiring dengan menciptakan citra dan reputasi dari identitas yang baru. Nama, slogan, dan logo merupakan elemen penting dalam merancang sebuah brand/merek, hal tersebut merupakan kebutuhan organisasi/instansi untuk membangun visi, misi, dan nilai-nilai organisasi dalam proses rebranding.

Strategi yang dilakukan adalah menyesuaikan masa kegiatan Penerimaan Mahasiswa Baru (PMB) dengan disisipi program pengenalan identitas baru dari STIKes 'Aisyiyah Yogyakarta berubah menjadi UNISA Yogyakarta. Hal ini dilakukan dengan memproduksi media tools sesuai 
kebutuhan promosi untuk disampaikan ke sekolah-sekolah dan kantor-kantor bimbingan belajar, dengan format elektronik, cetak, dan digital daring. Media tools yang digunakan meliputi: brosur, media sosial, website,stationery surat menyurat institusi, dan berbagai jenismerchandise/cinderamata.

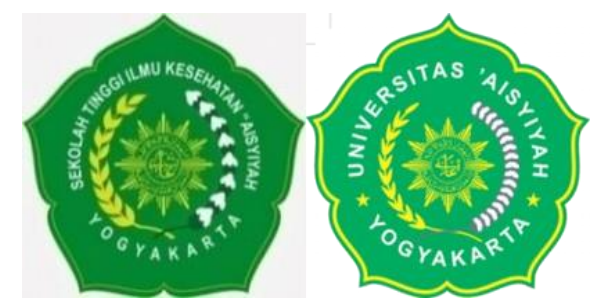

Gambar 5. Perubahan logo STIKes 'Aisyiyah menjadi Universitas Aisyiyah

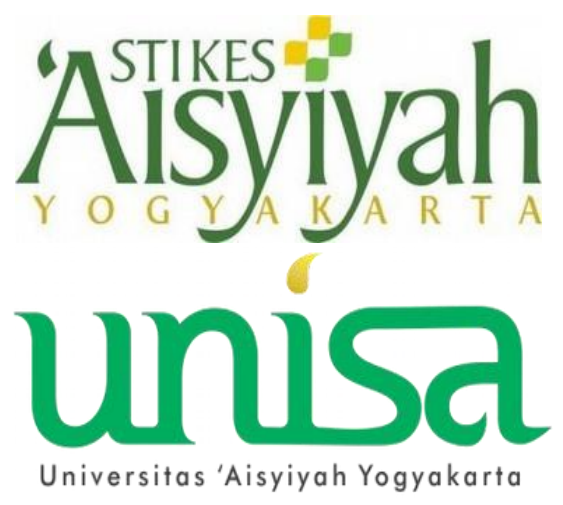

Gambar 6. Perubahan logo promosi/ brand name STIKes 'Aisyiyahmenjadi Universitas Aisyiyah

Dalam hal redesign, berubah menjadi universitas dengan penambahan dua fakultas berdampak pada perubahan budaya organisasi yang signifikan, yang salah satunya ditandai oleh pemberlakuan peraturan penggunan pakaian seragam perkuliahan. Seluruh program studi di lingkungan Fakultas Ilmu Kesehatan (FIKes) dalam menjalani perkuliahan diwajibkan memakai pakaian seragam yang sudah diatur sejak era STIKes 'Aisyiyah Yogyakarta. Peraturan berkenaan dengan pakaian seragam perkuliahan yaitu: nuansa warna hijau muda (Prodi S1 Ilmu Keperawatan), putih-biru muda (Prodi D3 Kebidanan), ungu (Prodi S1 Bidan Pendidik), dan putih-biru tua (Prodi S1 Fisioterapi).

Yuli menyampaikan persoalan desain logo dansejenisnya secara khusus dibebankan kepada unit humas sebagai satu-satunya unit kerja yang membidangi dan memiliki sumber daya terkait komunikasi visual dan desain. Pimpinan yayasan dan universitas hanya menginginkan warna dasarnya tetap hijau karena itu juga warnadasar yang menjadi identitas organisasi 'Aisyiyah.

Sinta menyampaikan berkaitan berkaitan dengan logo dan desain- desain identitas, humas membuat dua jenis logo yaitu logo utama institusi yang berbentuk seperi teratai segi lima dan logo khusus untuk promosi yaitu brand name yang berupa logo type bertuliskan Unisa. Logo utama dikelola mandiri oleh humas, sedangkanlogo brand name dibuat model kompetisi sebagai bagian dari strategi humas untuk mengenalkan diri kepada masyarakatYogyakarta.

\section{Brand Relaunch}

Brand Relaunch adalah peluncuran atau pemberitahuan identitas baru organisasi/instansi pemilik brand/merek kepada para pemangku kepentingan. Penggunaan berbagai jenis media cetak, elektronik, dan berbasis internet digunakan agar cakupan pengenalanidentitas baru bisa lebih luas dan menyasar semua lapisan masyarakat. Tahapan peluncuran identitas baru ini sebagai momentum penting, tanda kesiapan pemilik brand untuk beradu saing dengan pasar kembali.

Tindakan yang dilakukan STIKes 'Aisyiyah Yogyakarta adalah merilis informasi telah berubah bentuk organisasinya menjadi universitas, segera setelah surat edaran Menteri Riset Teknologi dan Pendidikan Tinggi resmi diterima jajaran pimpinan yangtertanggal 10 Maret 2016. 
Sehubungan dengan telah ditetapkan Keputusan Menteri Riset, Teknologi, dan Pendidikan Tinggi Nomor 109/KPT/I/2016 tanggal 10 Maret 2016 entang Perubahan Bentuk Sekolah Tinggi Ilmu Kesehatan Aisyiga Yogyakarta di Yogyakarta menjadi Universitas Aisyiyah Yogyakata di Yogyakarta yang diselenggarakan oleh Persyarikatan Muhammadiya Yogyakarta, bersama ini kami sampikan Salinan Kepus (a)

Gambar 7. Petikan SK Menristek Diktiperubahan STIKes menjadi Unisa

Setelah surat keputusan Menristek Dikti resmi terbit pada bulan Maret tentang perubahan bentuk organisasi dari sekolah tinggi menjadi universitas, UNISA Yogyakarta memanfaatkan situasi tersebut untuk kegiatan promosi melalui keaktifan mengikuti pameran pendidikan, kunjunganke sekolah-sekolah, dan penyebaran konten promosi cetak maupun digital.

Strategi tersebut dianggap jajaran pimpinan yayasan dan pimpinan universitas sebagai langkah jitu, karena masa Penerimaan Mahasiswa Baru (PMB) berlangsung hingga pada bulan September. Sehingga sisa waktu enam bulan bisa dimanfaatkan untuk pengenalan identitasbaru yang implikasinya pada penerimaa mahasiswa baru pada sepuluh program studi yang baru yaitu: Analis Kesehatan, Teknik Radiodiagnostik, Arsitek, Bioteknologi, Akuntansi, Manajemen, Administrasi Publik, Komunikasi, dan Psikologi.

Sinta menyatakan, dengan diterbitkannya surat ijin operasional baru dari Kemenristek Dikti terkait perubahan menjadi universitas, humas memiliki satu program kerja utama yaitu rebranding. Hal ini dikarenakan, perubahan yang dialami STIKes 'Aisyiyah meliputi pergantian nama, penambahan jenis produk/layanan, dan perubahan budaya organisasi. Maka humas berkewajiban mendesain strategi branding yang tepat, dan ini dilakukan melalui program rebranding. Pemilihan nama Unisa juga menjadi modal awal yangtepat, karena nama Unisa merujuk pada salah satu surat pada Alquran yang artinya perempuan-perempuan yaitu surat An- Nisa. Unisa dari An-Nisa sudah sesuai dengan nilai inti organisasi 'Aisyiyah yaituorganisasi Islam perempuan.
Proses relaunch pada UNISA dimanfaatkan sebagai proses membangun kesadaran merek (brand awareness) di benak pemangku kepentingan internal dan eksternal. Secara formal, relaunch hanyasatu kali bertepatan dengan penyerahan SK Menristek Dikti terkait perubahan STIKes menjadi UNISA. Namun, Biro Humas dan Protokoler UNISA membangun strategy relaunch untuk brand awareness dengan memanfaatkan momentum strategis yang memiliki nilai berita tinggi. Sehingga dampak publikasi informasi yang strategis juga meningkatkan kesadaran pemangku kepentingan internal dan eksternal tentang transformasi menjadi UNISA terbukti berkembang positif.

Warsiti menyampaikan, surat ijin operasional universitas baru terbit pada 10 Maret 2016, ini menjadi tantangan dan peluang Unisa karena surat resmi turun masih dalam masa penerimaan mahasiswa baru. Pimpinan rektora berkoordinasi dengan pimpinan yayasan dan unit humas mengadakan konferensi pers terkait peluncuran identitas baru menjadi Unisa pada tanggal 18 Maret 2016 setelah surat ijin operasional resmi dirilis. Materi peluncuran nama dan identitas baru sudah dicicil dan disiapkan sebelumnya oleh tim humas.

Siti menyampaikan, meski telah menjadi universitas, Unisa masih butuh penyesuaian terhadap perubahaninstitusi ini. Meski demikian, secara substansi, Unisa siap memberikan pendidikan pada level universitas.

Dengan melakukan rebranding pimpinan organisasi/instansi berharap agar dapat memulihkan dan/atau membangun kesetiaan pelanggan yang lebih optimal yang belum bisa dicapai dengan identitas brand/merek yang lama. Rebranding menjadi strategi pimpinan untuk meningkatkan pelayanan, termasukmerubah logo dan nama yang bertujuan agar mudah diingat oleh pemangku kepentingannya baik internal maupun eksternal. 
Tindakan rebranding bukan hanya sekedar untuk menutupi kecacatan produk, skandal buruk yang terjadi pada organisasi, dan citra negatif. Namun, dalam rebranding/revitalisasi brand/merek harus berbasis riset dan analisis mendalam, agar dampaknya lebih baik dari brand/merek sebelumnya dan logo yang diluncurkan harus singkat, jelas, mudah diucapkan dan diingat (Prayudi, 2019). Halini merupakan pekerjaan inti penentu kebijakan level manajerial khususnya divisi humas. Divisi humas, idealnya berada pada posisi yang dekat dengan pimpinan tinggi agar prinsip kolaboratif strategis kehumasan bisa terwujud dengan tujuan utama menaikkan citra dan reputasi yang positif atas pemberlakuan identitasyang baru.

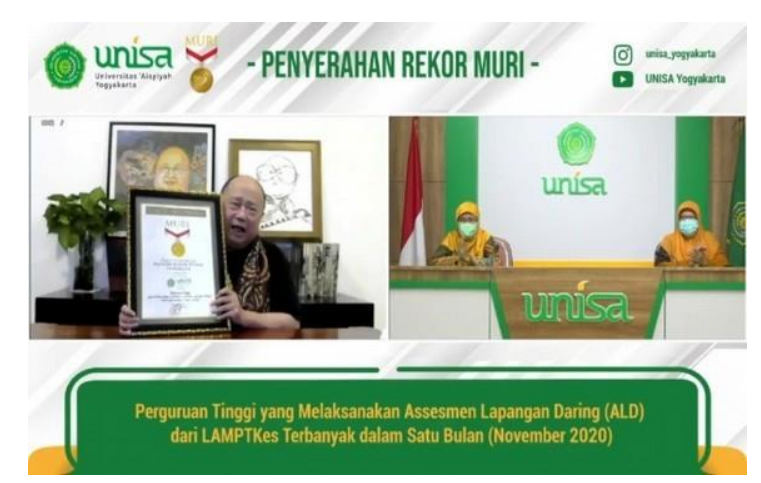

Gambar 8. UNISA Pecah Rekor MURI

Jajaran pimpinan UNISA serius menjalani perubahan bentuk organisasi menjadi universitas. 5 tahun transformasi menjadi universitas, program rebranding terbukti membuahkan hasil yang positif. UNISA meraih berbagai prestasi dan yang paling monumental adalah pemecahan rekor MURI yaitu dengan menjalani Assesmen Lapangan Daring (ALD) terkait proses reakreditasi pada program studi Sarjana Kebidanan, Sarjana Keperawatan, Sarjana Gizi, dan Sarjana Keperawatan Anastesi. Pelaksanaan ALD dilakukan terbanyak yaitu 4 ALD hanya dalam waktu 1 bulan. Pelaksanaan ALD dilaksanakanoleh Lembaga Akreditasi Mandiri Perguruan Tinggi Kesehatan (LAMPTKes) dan penyerahan sertifikat rekor MURI langsung oleh CEO dan Penggagas MURI yaitu Jaya Suprana.
Pada kegiatan pemecahan rekorMURI, Biro Humas dan Protokoler UNISA menjalankan tugas dan fungsinya sekaligus dalam dua peran yaitu teknisi komunikasi dan pengelola informasi. Praktisi humas melihat peluang langka yang tidak diperoleh kampus lain yaitu pelaksanaan assesmen lapangan daring secara beruntun 4 program studi dalam kurun waktu satu bulan.

Sinta menyampaikan, pencapaian rekor MURI menjadi bagian dari program kerja panjang yaitu rebranding dari STIKes menjadi Unisa. Rekor ini menjadi bukti bahwa Unisa memenuhi kompetensi bahkan melebihi standar sebagai universitas yang tergolong masih baru.

Kegiatan pemecahan rekor MURI tersebut memiliki nilai berita yang tinggi dan berpotensi berdampak besar pada konsep brand awareness keberadaan Unisa pada usia 5 tahun yaitu satu masa perencanaan strategis (renstra) yang pada tahap ini disebut dengan tahap Unisa Tumbuh. Berdasarkan hal tersebut, praktisihumas Unisa mendesain dan memberi masukan kepada para jajaran pimpinan universitas guna diusulkan pemecahan rekor MURI.

\section{PENUTUP}

Program kerja rebranding yang dilaksanakan oleh unit humas melibatkan unsur pimpinan yayasan dan pimpinan universitas. Posisi unit humas ideal karena bisa mengakomodir kebutuhan pimpinandan bawahan karena humas juga dilibatkandalam diskusi terkait program pimpinan mengembangkan STIKes menjadiUniversitas. Peran humas secara struktur organisasi dan secara bidang tugas pokok sesuai dengan dasar teori manajemen humas.

Praktisi humas pada unit kerja Biro Humas dan Protokoler (BHP) Unisa menjalankan tugas pokok dan fungsinya dalam program kerja rebranding STIKes berubah menjadi Universitas 'Aisyiyah (Unisa) Yogyakarta berlaku sebagai teknisi 
komunikasi dan pengelolainformasi.

Pada fungsi sebagai teknisi komunikasi, praktisi humas Unisa bertugas membuat perlengkapan publikasi informasi meliputi: rilis berita, audio visual, desain vektor, foto, perangkat cinderamata, dan tata kelolakeprotokoleran pemangku kepentingan eksternal. Humas sebagai teknisi komunikasi tidak terlibat dalam proses penentuan kebijakan. Selain itu, humas sebagai teknisi komunikasi juga sekaligus mengelola komunikasi publik dengan membangun kemitraan dengan institusimedia pemberitaan.

Pada fungsi sebagai pengelola informasi, praktisi humas Unisamenjalankan tugas secara sistematis danterstruktur dalam merencanakan dan mengatur program kerja kehumasan yang tujuan utamanya mewujudkan visi organisasi. Humas sebagai pengelola informasi berperan sebagai pemberi saran/ masukan kepada jajaran pimpinan yayasandan pimpinan universitas berdasarkan padaanalisis situasi dari data yang diperoleh praktisi humas melalui program kerja riset atau evaluasi rutin yang dilakukannya. Jajaran pimpinan memberikan otonomi kepada praktisi humas untuk mendesain program kerja yang luarannya bias dijadikan usulan strategis yang bertujuan membantu kelancaran programpengembangan jangka pendek, menengah, dan panjang pada organisasi Unisa.

\section{DAFTAR PUSTAKA}

Abrudan, M. (2009). Research Methods in Communication Sciences. Studia Universitatis Babes-BolyaiEphemerides, 54(1), 117-142.

Beresford, S., \& Schwarz, A. (2014). Managing public relations. In Entertainment Management: Towards Best Practice (pp. 60-76). https://doi.org/10.2307/j.ctv5jxpgx.1 $\underline{0}$
Broom, G. M., \& Sha, B.-L. (2013). Cutlip\& Center's Effective Public RelationsEleventh Edition.

Depag, R. (2007). Alquran pdf terjemahan. Al-Qur'an Terjemahan, 1-1100.

Flecknoe, S. J., Choate, J. K., Davis, E. A., Hodgson, Y. M., \& Johanesen, P. A. (2017). Redefining academic identity in an evolving higher education landscape. Journal of University Teaching and Learning Practice, 14(2).

Goi, C., \& Goi, M.-T. (2011). Review on Models and Reasons of Rebranding. International Conference on Social Science and Humanity, 5, 445-449. http://www.ipedr.com/vol5/no2/99H10243.pdf

Keller, K. L. (2007). Marketing Management12. vydání. January 2006, 1-5. http://books.google.cz/books? id=pkWsyjLsfGgC

Miller, D., Merrilees, B., \& Yakimova, R. (2014a). Corporate rebranding: An integrative review of major enablers and barriers to the rebranding process. International Journal of Management Reviews, 16(3), 265289.

https://doi.org/10.1111/ijmr.12020

Miller, D., Merrilees, B., \& Yakimova, R. (2014b). Corporate rebranding: An integrative review of major enablers and barriers to the rebranding process. International Journal of Management Reviews, 16(3), 265289.https://doi.org/10.1111/ijmr.120 $\underline{20}$

Muzellec, L., \& Lambkin, M. (2008). Corporate rebranding and the implications for brand architecture management: The case of Guinness (Diageo) Ireland. Journal of StrategicMarketing, 16(4), 283-299. 
https://doi.org/10.1080/0965254080 $\underline{2264124}$

Nicoli Nicholas and Marcos Komodromos. (2013). Principles and Practice of Public Relations. In Practice.

Paasi, A. (2018). Borderless worlds and beyond: Challenging the statecentric cartographies. Borderless Worlds for Whom?: Ethics, Moralities and Mobilities, January, 21-36.

https://doi.org/10.4324/9780429427 $\underline{817-2}$

Prayudi. (2019). Public Relations Stratejik. In Komunikasi UPN Press (Vol. 80, Issue 20).

Rakhmat, J. (2004). Metode penelitian komunikasi. In International Journal of Adolescence and Youth (Vol. 3, Issue $1)$. http://dx.doi.org/10.1016/j.appdev.2 016.03.001\%250A https://www.bertels mannstiftung.de/fileadmin/files/Bst/ Publikationen/GrauePublikationen/ MT_Globalization_Report_2018.pdf \%250Ahttp://eprints.lse.ac.uk/ 43447/1/India_globalisation\%252C society and inequali

Sharma, S. K., Palvia, S. C. J., \& Kumar, K. (2017). Changing the landscape of higher education: From standardized learning to customized learning. Journal of Information Technology Case and Application Research, 19(2), 75-80. https://doi.org/10.1080/15228053.20 17.1345214 